\title{
Validation of sensitive spectrophotometric method for determination of Salmeterol xinafoate and Fenoterol hydrobromide via o-Phenanthroline and iron complexation
}

\author{
Mohamed A. Hammad ${ }^{1}$, Mahmoud A. Omar ${ }^{1}$, Mohamed Awad ${ }^{2 *}$ \\ ${ }^{1}$ Analytical Chemistry Department, Faculty of Pharmacy, Minia University, Minia, Egypt. \\ ${ }^{2}$ Pharmaceutical analytical Chemistry Department, Faculty of Pharmacy, Al-Azhar University, Assiut branch, Assiut, Egypt.
}

\begin{tabular}{l} 
ARTICLE INFO \\
\hline Article history: \\
Received on: 10/02/2017 \\
Accepted on: 01/04/2017 \\
Available online: $30 / 06 / 2017$ \\
\hline Key words: \\
Salmeterol; Fenoterol; Iron; \\
o-phenanthroline; \\
spectrophotometry.
\end{tabular}

\begin{abstract}
A Simple, accurate and sensitive spectrophotometric method has been established and validated for the determination of two selective beta-2 agonist drugs namely; Salmeterol xinafoate and Fenoterol hydrobromide in their pure forms and pharmaceutical preparations. The proposed method is based on the ability of studied drugs to reduce iron (III) in (o-phenanthroline)-iron (III) complex to form highly stable colored tris (ophenanthroline)-iron (II) complex that can be measured spectrophotometrically at $510 \mathrm{~nm}$. Different variables affecting the reaction were studied and optimized to ensure maximum sensitivity of the method. The developed method was found to obeys Beer's law in the concentration range of (0.7-7.0) and (1.0-8.0) $\mu \mathrm{g} \mathrm{mL} \mathrm{mL}^{-1}$ with quantitation limits 0.523 and $0.705 \mu \mathrm{g} \mathrm{mL}^{-1}$, for Salmeterol and Fenoterol, respectively. The suggested method was completely validated according to the ICH guidelines and successfully applied for determination of the studied drugs in their pharmaceutical preparations with high accuracy.
\end{abstract}

\section{INTRODUCTION}

Salmeterol xinafoate (SAL); $(R S)$-5-salicyl alcohol 1hydroxy-2-naphthoate and Fenoterol hydrobromide (FEN);1(3,5-Dihydroxyphenyl)-2 -(4-hydroxy- $\alpha$-methylphenethylamino) ethanol hydrobromide, are selective beta- 2 agonist drugs that are widely used for the treatment of Asthma and chronic obstructive pulmonary diseases due to their direct sympathomimetic action on the smooth muscles (Martindale, 2005). Many analytical procedures have been reported in the literature for determination of the cited drugs in their pharmaceutical preparations as well as biological fluids. These methods include

\footnotetext{
* Corresponding Author

Email: ph_awad @yahoo.com
}

Spectroscopic (Abounassif and Abdel-Moety, 1989; Chowdary and Devala Rao, 1997; Thea Sufernent, 1998; Chowdary and Devala Rao, 1999; AL-Malaq et al., 2000; Kumar et al., 2000; Reddy et al., 2000; El-Shabrawy et al., 2003; Beyene et al., 2004; Eid, 2007; Zamuner et al., 2008; Samir et al., 2012; Soliman and Abdel Moety, 2014), HPLC(Nayak et al., 1996; Wang et al., 2007; Siluk et al., 2008), HPTLC (Kasaye et al., 2010; Ahmed and Youssef, 2011)and electrochemical methods (Radi, 2006). However most of these methods require sophisticated instruments, high cost reagents, or require the use of organic solvents which have harmful effects on the analysts.

So there was a need for the development of new sensitive, simple and cost effective method for the determination of cited drugs in their dosage forms that can be used in routine work analytical laboratories. 


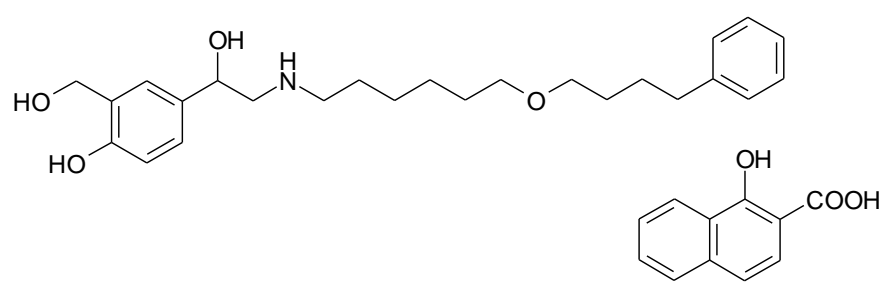

SAL (a)

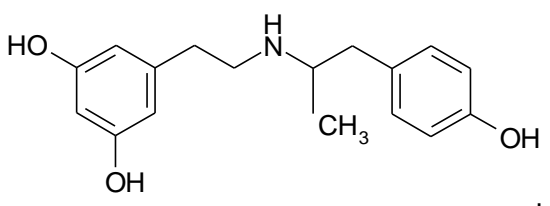

FEN (b)

Fig. 1: Chemical structure of (a) Salmeterol xinafoate and (b) Fenoterol hydrobromide.

\section{EXPERIMENTAL}

\section{Apparatus}

A Shimadzu UV-1601 PC spectrophotometer (Tokyo, Japan) with $1 \mathrm{~cm}$ quartz cell, MLW type thermostatically controlled water bath (Memmert GmbH, Schwabach, Germany) and Digital analytical balance (AG 29, Mettler Toledo, and Glattbrugg, Switzerland).

\section{Materials and reagents}

All materials were of analytical reagent grade and all solutions were prepared with double distilled water.

Salmeterol xinafoate pure sample was kindly provided by ADCO, CO, (Cairo, Egypt), Fenoterol hydrobromide provided by Sigma pharmaceutical industries (Quisna, Egypt). 1,10phenanthroline was purchased from Sigma Aldrich Chemie $\mathrm{GmbH}$ (Steinheim, Germany), ferric ammonium sulfate dodecahydrate, methanol, ethanol, acetone and dimethyl formamide (DMF) were purchased from El- Nasr chemical CO, (Cairo, Egypt).Fe (III)- oPhenanthroline reagent (Phen) was freshly prepared daily by mixing $0.198 \mathrm{~g}$ of o-Phenanthroline with $2 \mathrm{~mL} 1.0 \mathrm{M} \mathrm{HCl}$ and 0.16 $\mathrm{g}$ of ferric ammonium sulfate dodecahydrate and diluting with distilled water to $100 \mathrm{~mL}$ (Amin et al., 1999; Homoda et al., 2016).

\section{Preparation of standard solutions}

Stock standard solutions (1.0mg. $\left.\mathrm{mL}^{-1}\right)$ of each studied drug were prepared by dissolving appropriate amount of authentic powder in methanol and distilled water for Salmeterol xinafoate and Fenoterol hydrobromide, respectively. Further dilutions were made using distilled water for preparing standard working solutions.

\section{General analytical procedure}

Into a series of $10-\mathrm{mL}$ stoppered test tubes, appropriate volumes of working drug solutions covering final concentration range (0.7-7.0) and (1.0-8.0) $\mu \mathrm{g} \mathrm{mL} \mathrm{m}^{-1}$ for SAL and FEN. respectively were added were added, followed by the addition of 2 $\mathrm{mL}$ (Phen) reagent, shaken well and transferred to thermostatically controlled water bath kept at $70{ }^{\circ} \mathrm{C}$ for 15 minutes. The tubes were cooled using ice bath and their contents were transferred quantitatively into $10-\mathrm{mL}$ volumetric flasks and completed to the volume with distilled water. The red color formed was measured at $510 \mathrm{~nm}$ against reagent blank treated similarly omitting drug addition.

\section{Preparation of pharmaceutical dosage forms}

Metrovent $^{\circledR}$ inhaler labeled to contain $25 \mu \mathrm{g}$ SAL per actuation was shaken well and 200 actuations (the whole content of the inhaler) were actuated in $100 \mathrm{~mL}$ beaker containing $40 \mathrm{~mL}$ of methanol. The mouth piece of the inhaler was immersed beneath the methanol to ensure complete delivery of the drug without any waste. The contents of the beaker was gently warmed at $50^{\circ} \mathrm{C}$ in thermostatically controlled water bath to expel propellants, the contents of the beaker was then transferred into $50 \mathrm{~mL}$ volumetric flask and completed to the volume with methanol to obtain final concentration of $100 \mu \mathrm{g} \cdot \mathrm{mL}^{-1}$, and then general analytical procedure was followed.

Bronotrol $^{\circledR}$ syrup labeled to contain $2.5 \mathrm{mg} / 5 \mathrm{~mL}$ FENwas prepared by transferring $100 \mathrm{~mL}$ of syrup into a $250-\mathrm{mL}$ separating funnel, 5-mL of concentrated ammonia were added and (FEN) was extracted with $30-\mathrm{mL}$ chloroform $(5 \mathrm{~mL} \times 6$ times). The chloroform layer containing the studied drug was collected over anhydrous sodium sulfate organic layer, evaporated to dryness and the residue was dissolved in methanol and transferred into $50-\mathrm{mL}$ volumetric flask and completed to the volume with distilled water to obtain final concentration of $1 \mathrm{mg} \cdot \mathrm{mL}^{-1}$, and then general analytical procedure was performed.

\section{RESULTS AND DISCUSSION}

SAL and FEN contain phenolic and alcoholic hydroxyl groups which are known for their effective reducing power(Pesez, 1974; Firuzi et al., 2005). The reduction of ferric to ferrous had been widely used for spectrophotometric determination of phenolic drugs in many occasions (Reddy et al., 2000; Gousuddin et al., 2011). In this study, we utilized the presence of phenolic and hydroxyl groups in the studied drugs to quantitatively reduce the $\mathrm{Fe}$ (III) in the Fe (III)-o-Phenanthroline complex toform stable red colored chromogen corresponding to Fe (II) o-Phenanthroline complex (Fig 2) that can be measured spectrophotometrically at $510 \mathrm{~nm}$, Fig 3.

\section{Optimization of variables}

Different experimental parameters affecting reaction development and stability of the reaction products were carefully studied and optimized. These factors were changed individually, while the others were kept unchanged. These factors include volume of Phen reagent, heating time and temperature, $\mathrm{pH}$ of the reaction media and effect of diluting solvents. 


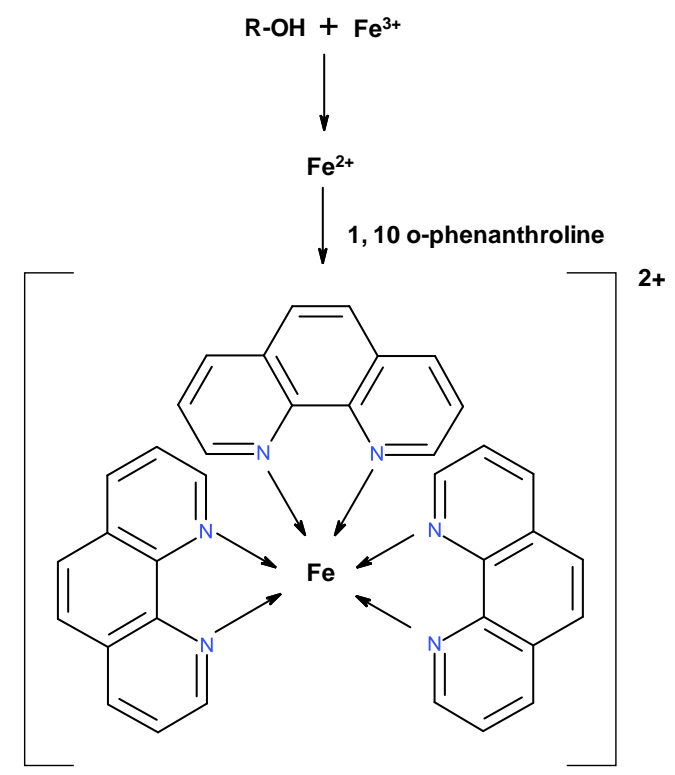

Fig. 2: Suggested reaction mechanism of studied drugs (R-OH) by the proposed spectrophotometric method to form red colored [Fe (II) - ophenanthroline] complex chromogen.

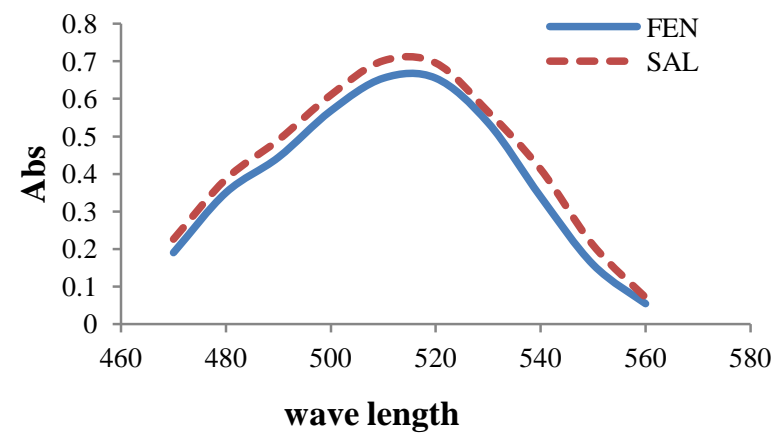

Fig. 3: Absorbance spectrum of the reaction products of studied drugs $(5 \mu \mathrm{g}$ $\left.\mathrm{mL}^{-1}\right), \mathrm{Fe}$ (III) \& o-phenanthroline by the proposed spectrophotometric method.

\section{Effect of reagent volume}

Different volumes of (Phen) reagent were added to obtain maximum color development and hence achieve high sensitivity of the method. It was found that $2 \mathrm{~mL}$ of the reagent gave maximum absorbance and any further increase did not affect the color development, Fig 4.

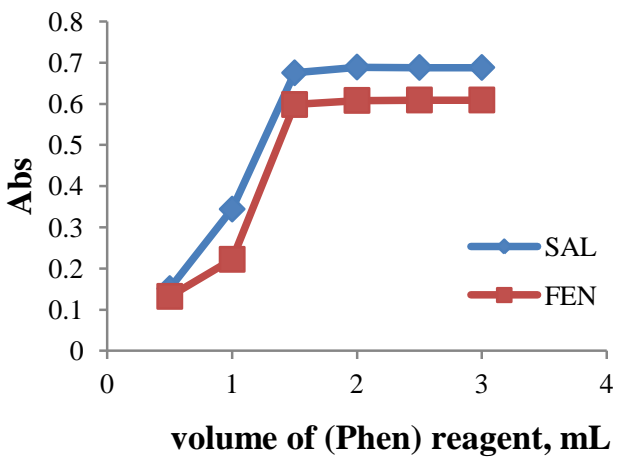

Fig. 4: Effect of (Phen) reagent volume on the reaction products of Salmeterol and Fenoterol $\left(5 \mu \mathrm{g} \mathrm{mL}^{-1}\right)$ by the proposed spectrophotometric method.

\section{Effect of heating time and temperature}

Different temperatures were studied to select the best conditions for the developed procedure. The reaction was allowed to proceed at room temperature and it took more than two hours to develop the desired color which is not convenient for routine analysis, so in order to save time, the reaction was performed in a thermostatically controlled water bath at different temperatures and different time intervals. It was found that best conditions for the suggested method areheating the reaction medium at $70{ }^{0} \mathrm{C}$ for 15 minutes. Longer periods of time did not affect color development and higher temperatures caused slight decrease in the absorbance, Fig (5 and 6).

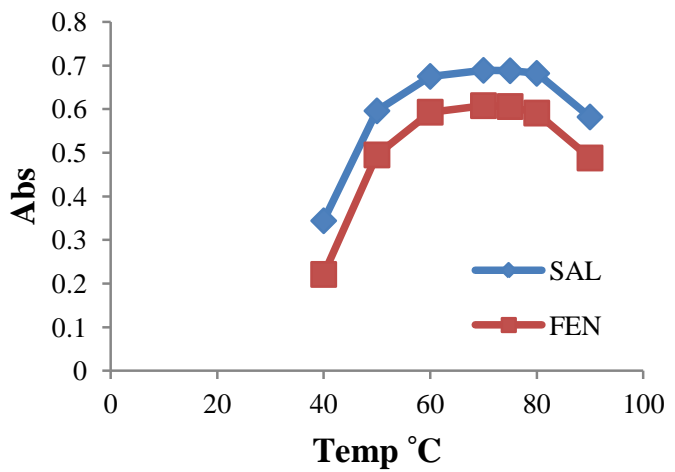

Fig. 5: Effect of temperature on the reaction between (Phen) reagent and studied drugs $\left(5 \mu \mathrm{g} \mathrm{mL}^{-1}\right)$ by the proposed spectrophotometric method.

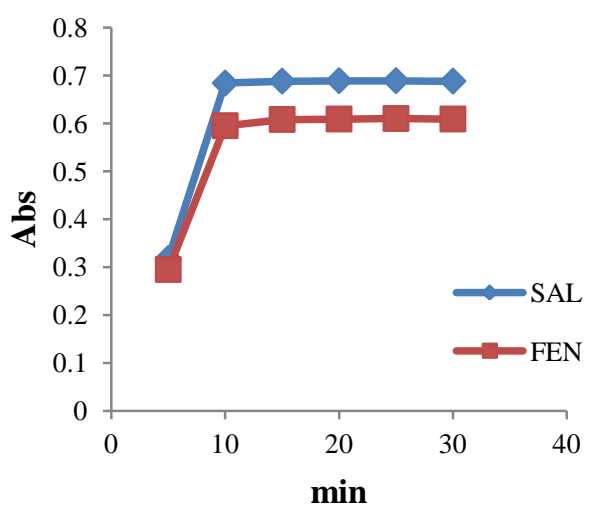

Fig. 6: Effect of heating time on the reaction between (Phen) reagent and studied drugs $\left(5 \mu \mathrm{g} \mathrm{mL}^{-1}\right)$ by the proposed spectrophotometric method.

\section{Effect of pH}

It was reported that the reaction of o-phenanthroline with iron proceeded better in acidic $\mathrm{pH}$ (Homoda et al., 2016). However, the effect of $\mathrm{pH}$ on the reaction products was also studied and the results showed no effect on the color development. So for simplicity of the method no buffer was added and the reaction was kept to proceed in acidic medium provided by $\mathrm{HCl}$ content in Phen reagent.

\section{Effect of diluting solvent}

Different solvents such as water, methanol, ethanol, acetone, acetonitrile and DMF were studied in order to select the 
most suitable solvent for dilution. Methanol and ethanol did not affect the absorbance significantly while acetone and DMF caused turbidity in the flask affecting the color of the complex. So water was used as the best solvent that gave better results making the method simpler and more economic.

\section{Validation of the proposed method}

The proposed spectrophotometric method was validated according to the ICH guide lines regarding accuracy, precision, Limits of quantitation and detection and robustnessin order to prove that the performance characteristics of the method meet the requirements for the intended analytical applications( $\mathrm{ICH}$ Guidelines, 2005).

\section{Linearity and concentration range}

In this work, the general analytical procedure was performed on a series of standard drug solutions having concentrations ranging from (0.7-7.0) and (1.0-8.0) $\mu \mathrm{g} \cdot \mathrm{mL}^{-1}$ for Salmeterol and Fenoterol, respectively. The whole set of experiments were carried out within this range to ensure the validation of the proposed procedure. Linear calibration was obtained by plotting the Absorbance at $510 \mathrm{~nm}$ versus the drugs concentration within the specified range. Statistical treatment of the data was carried out using linear regression analysis and the analytical parameters were calculated, the correlation coefficient was 0.9996 for FEN and SAL indicating good linearity, Table 1.

Table 1: Analytical parameters of the proposed spectrophotometric method for determination of the investigated drugs.

\begin{tabular}{lll}
\hline Parameter & SAL & FEN \\
\hline$\lambda \max (\mathrm{nm})$ & 510 & 510 \\
Concentration range $\left(\mu \mathrm{g} \mathrm{mL}^{-1}\right)$ & $0.7-7.0$ & $1.0-8.0$ \\
Correlation coefficient $(\mathrm{r})$ & 0.9996 & 0.9996 \\
Determination coefficient $\left(\mathrm{r}^{2}\right)$ & 0.9993 & 0.9992 \\
Slope & 0.1144 & 0.1024 \\
Intercept & 0.1136 & 0.09205 \\
SD the intercept $(\mathrm{Sa})$ & 0.00598 & 0.00722 \\
SD the slope $\quad(\mathrm{Sb})$ & 0.00156 & 0.00144 \\
LOD $\left(\mu \mathrm{g} \mathrm{mL}^{-1}\right)$ & 0.173 & 0.232 \\
LOQ $\left.(\mu \mathrm{g} \mathrm{mL})^{-1}\right)$ & 0.523 & 0.705 \\
\hline
\end{tabular}

LOD: Limit of detection, LOQ: Limit of quantitation.

Table 2: Evaluation of the Accuracy of investigated analytical Procedure at five Concentration levels within the specified range.

\begin{tabular}{|c|c|c|c|c|c|c|}
\hline \multirow[b]{2}{*}{ 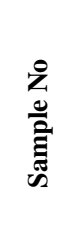 } & \multicolumn{3}{|c|}{ SAL } & \multicolumn{3}{|c|}{ FEN } \\
\hline & 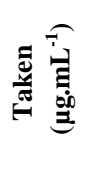 & 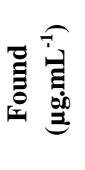 & 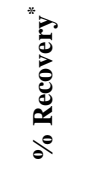 & 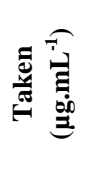 & 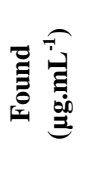 & 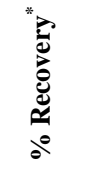 \\
\hline 1 & 0.70 & 0.70 & 100.14 & 1.00 & 1.00 & 100.32 \\
\hline 2 & 1.00 & 1.00 & 100.02 & 3.00 & 3.00 & 100.25 \\
\hline 3 & 3.00 & 3.00 & 100.04 & 5.00 & 5.00 & 100.16 \\
\hline 4 & 5.00 & 5.00 & 100.11 & 7.00 & 6.99 & 99.87 \\
\hline 5 & 7.00 & 7.21 & 102.19 & 8.00 & 8.01 & 100.17 \\
\hline Mean & & & 100.5 & & & 100.15 \\
\hline SD & & & 0.94 & & & 0.17 \\
\hline
\end{tabular}

\section{Accuracy and precision}

Accuracy was checked at five concentration levels within the specified range. Three replicate measurements were recorded at each concentration level. The results were presented as percentage recovery \pm standard deviation. The obtained results show good agreement between the measured and true value indicating high accuracy of the proposed method, Table 2.

Precision was examined at three concentration levels; three replicate measurements were recorded at each concentration level; both inter-day and intra-day precision were evaluated and their results were summarized in Table 3 . The calculated relative standard deviations were below $2 \%$ indicating excellent precision of the proposed procedure at both level of repeatability and intermediate precision.

Table 3: Evaluation of interday and intraday precision of the proposed method for determination of cited drugs.

\begin{tabular}{|c|c|c|c|c|c|c|}
\hline \multirow[t]{2}{*}{$\begin{array}{c}\text { Precision } \\
\text { level }\end{array}$} & \multicolumn{2}{|c|}{$\begin{array}{c}\text { Conc } \\
\left(\mu \mathrm{g} \mathrm{mL}^{-1}\right)\end{array}$} & \multicolumn{2}{|c|}{$\%{ }^{*}$ Recovery \pm SD } & \multicolumn{2}{|c|}{ \%RSD } \\
\hline & SAL & FEN & SAL & FEN & SAL & FEN \\
\hline \multirow{3}{*}{ Intraday } & 1 & 3 & $98.78 \pm 0.88$ & $99.49 \pm 0.66$ & 0.89 & 0.66 \\
\hline & 3 & 5 & $99.37 \pm 0.75$ & $99.89 \pm 0.41$ & 0.75 & 0.41 \\
\hline & 5 & 7 & $99.81 \pm 0.59$ & $99.79 \pm 0.39$ & 0.59 & 0.39 \\
\hline \multirow{3}{*}{ Interday } & 1 & 3 & $99.26 \pm 1.1$ & $99.58 \pm 0.63$ & 1.1 & 0.63 \\
\hline & 3 & 5 & $99.58 \pm 0.73$ & $100.71 \pm 1.05$ & 0.73 & 1.04 \\
\hline & 5 & 7 & $99.75 \pm 0.30$ & $99.75 \pm 0.65$ & 0.30 & 0.65 \\
\hline
\end{tabular}

*Mean of three determinations.

\section{Limit of detection (LOD) and limit of quantitation (LOQ)}

The limits of detection (LOD) and quantification (LOQ) were calculated based on standard deviation of response and the slope of calibration curve using the equations; $\mathrm{LOD}=3.3 \mathrm{\sigma} / \mathrm{S}$ and $\mathrm{LOQ}=10 \sigma / \mathrm{S}$, where $\mathrm{S}$ is the slope of the calibration curve and $\sigma$ is the standard deviation of intercept. The results were presented in Table 1. The limit of quantitation was $0.705 \mu \mathrm{g} \mathrm{mL}^{-1}$ and $0.523 \mu \mathrm{g}$ $\mathrm{mL}^{-1}$ for Fenoterol and Salmeterol, respectively indicating high sensitivity of the proposed method compared with the reported reversed phase HPLC method for determination of salmeterolmetered dose inhalers (with detection level $2 \mu \mathrm{g} \mathrm{mL}^{-1}$ ) (Nayak et al., 1996), and the reported spectrophotometric method for Fenoterol(Abounassif and Abdel-Moety, 1989). The high sensitivity of the proposed method gave it the advantage over other methods that require sophisticated and expensive instruments.

\section{Robustness}

Robustness of the suggested procedure was assessed by evaluating the influence of small variation in experimental variables (volume of reagent, temperature, and heating time). The results presented in Table 4, indicated that small variations in any of these variables did not significantly affect the performance of the suggested procedure. This gave an indication for the reliability of the proposed method during routine work. 
Table 4: Robustness study of the proposed method for determination studied drugs.

\begin{tabular}{|c|c|c|}
\hline Variation & \multicolumn{2}{|c|}{ \% Recovery ${ }^{*} \pm$ SD } \\
\hline \multirow{2}{*}{ Optimum conditions } & SAL & FEN \\
\hline & $100.05 \pm 0.13$ & $100.07 \pm 0.09$ \\
\hline \multicolumn{3}{|l|}{ 1-Effect of volume of reagent } \\
\hline $1.5 \mathrm{~mL}$ & $99.76 \pm 0.17$ & $99.84 \pm 0.15$ \\
\hline $2.5 \mathrm{~mL}$ & $99.97 \pm 0.13$ & $100.06 \pm 0.12$ \\
\hline \multicolumn{3}{|l|}{ 2-Effect of temperature } \\
\hline $65^{\circ} \mathrm{C}$ & $99.56 \pm 0.28$ & $99.80 \pm 0.08$ \\
\hline $75{ }^{\circ} \mathrm{C}$ & $100.00 \pm 0.10$ & $100.06 \pm 0.12$ \\
\hline \multicolumn{3}{|l|}{ 3-Effect of heating time } \\
\hline $10 \mathrm{~min}$ & $99.79 \pm 0.27$ & $99.93 \pm 0.07$ \\
\hline $20 \mathrm{~min}$ & $100.03 \pm 0.12$ & $100.06 \pm 0.16$ \\
\hline
\end{tabular}

*Mean of five determinations.

Table 5: Comparison between the proposed and reported methods methods (Abounassif and Abdel-Moety, 1989; Samir et al., 2012) for determination of cited drugs in pharmaceutical preparations.

\begin{tabular}{ccccc}
\hline \multirow{2}{*}{ Dosage form } & \multicolumn{2}{c}{${ }^{\%}$ Recovery ${ }^{*} \pm$ SD } & & \\
\cline { 2 - 4 } & Proposed & Reported & & \\
\hline $\begin{array}{c}\text { Metrovent }{ }^{\circledR} \text { inhaler } \\
(25 \mu \mathrm{g} \mathrm{Sal} / \text { actuation })\end{array}$ & $100.54 \pm 0.5$ & $100.25 \pm 0.85$ & 1.17 & 2.85 \\
\hline $\begin{array}{c}\text { Bronotrol }{ }^{\circledR} \text { syrup } \\
(2.5 \mathrm{mg} \mathrm{Fen} / 5 \mathrm{~mL})\end{array}$ & $100.24 \pm 0.47$ & $99.68 \pm 0.67$ & 1.54 & 2.01 \\
\hline
\end{tabular}

"Mean of five determinations.

a: The tabulated values of $(\mathrm{t})$ and $(\mathrm{F})$ values at $95 \%$ confidence limit are 2.78 and 6.39 , respectively.

\section{Application to pharmaceutical preparations}

The proposed method was successfully applied for determination of the investigated drugs in their pharmaceutical preparations. The results of the proposed method were statistically compared with those of the reported methods (Abounassif and Abdel-Moety, 1989; Samir et al., 2012) using student's t-test and $F$-test with respect to accuracy and precision. There was no significant difference between the proposed and reported methods as the calculated values did not exceed the theoretical values at 95\% confidence level, Table 5. This indicates good level of precision and accuracy of the proposed method.

\section{CONCLUSION}

In this study, accurate and sensitive spectrophotometric method was established for determination of Salmeterol xinafoate and Fenoterol hydrobromide with limits of detection 0.173 and $0.232 \mu \mathrm{g} \mathrm{mL} \mathrm{mL}^{-1}$, respectively. The proposed method was successfully applied for determination of investigated drugs in their dosage formulations. The suggested method is simple, cost effective and can be used for routine analysis in any analytical laboratory with good accuracy and precision.

\section{Financial support and sponsorship: Nil.}

Conflict of Interests: There are no conflicts of interest.

\section{REFERENCES}

Abounassif M A, Abdel-Moety E A. Spectrophotometric quantification of fenoterol hydrobromide in tablets and inhalation aerosol Acta-Pharm-Jugosl, 1989; 39: 359-363.

Ahmed H, Youssef N. Validated HPTLC method of salmeterol xinafoate determination in inhaled pharmaceutical product and spiked human urine. Journal of Planar Chromatography 2011; 24: 423-427.

AL-Malaq H A, AL-Majed A A, Belal F. A Stability-indicating spectrophotometric method for the determination of fenoterol in pharmaceutical preparations. Analytical letters, 2000; 33: 1961-1974.

Amin A S, Zaky M, Khater H M, El-Beshbeshy A M. New Colorimetric methods for microdetermination of Melatonin in pure and in dosage Forms. Analytical letters, 1999; 32: 1421-1434.

Beyene N W, van Staden J F, Stefan R I. Determination of fenoterol hydrobromide by sequential injection analysis with spectrophotometric detection. Analytica Chimica Acta, 2004; 521: 223-29.

Chowdary K P R, Devala Rao G. Spectrophotometric determination of salmeterol xinafoate with folin ciocalteau reagent. indian drugs, 1997; 34: 606-607

Chowdary K P R, Devala Rao G. Visible spectrophotometric method for the determination of salmeterol xinafoate. Indian Journal of Pharmaceutical Sciences, 1999; 61: 246-247.

Eid M. Spectrofluorimetric determination of fenoterol in pharmaceuticals. Journal of the Chinese Chemical Society, 2007; 54: 613617.

El-Shabrawy Y, Belal F, Sharaf El-Din M, Shalan S Spectrophotometric determination of fenoterol hydrobromide in pure form and dosage forms. Il Farmaco, 2003; 58: 1033-1038.

Firuzi O, Lacanna A, Petrucci R, Marrosu G, Saso L. Evaluation of the antioxidant activity of flavonoids by "ferric reducing antioxidant power" assay and cyclic voltammetry. Biochimica et Biophysica Acta (BBA)-General Subjects, 2005; 1721: 174-184.

Gousuddin M, Appala Raju S, Sultanuddin, Manjunath S. Development and validation of spectrophotometric methods for estimation of formoterol bulk drug and its pharmaceutical dosage forms. International Journal of Pharmacy and Pharmaceutical Sciences, 2011; 3: 306-309.

Homoda A M, Kamel M S, Elmorsy K. New spectrophotometric microdetermination of carbapenem antibiotics derivatives in pharmaceutical formulations. Journal of Taibah university for science, 2016; 10: 19-25.

ICH Guidelines, Q2 (R1): Validation of analytical procedures: text and methodology, International Conference on Harmonization (ICH) Geneva, 2005.

Kasaye L, Hymete A, Mohamed A M. HPTLC-densitometric method for simultaneous determination of salmeterol xinafoate and fluticasone propionate in dry powder inhalers. Saudi Pharm J, 2010; 18: 153-159.

Kumar G K, Chowdary K P R, Devala Rao G. Spectrophotometric determination of salmeterol xinafoate using diazotised sulphanilamide. The Antiseptic, 2000; 97:

Martindale: the complete drug reference, Royal Pharmaceutical Society of Great Britain London: Pharmaceutical Press, 2005.

Nayak V G, Belapure S G, Gaitonde C D, Sule A A. Determination of salmeterol in metered-dose and dry-powder inhalers by reversed-phase high performance liquid chromatography. J Pharm Biomed Anal, 1996; 14: 511-513.

Pesez M, Bartos, Jaroslav. Colorimetric and fluorimetric analysis of organic compounds and drugs, 1974.

Radi A. Applications of stripping voltammetry at carbon paste and chemically modified carbon paste electrodes to pharmaceutical analysis. Current Pharmaceutical Analysis, 2006; 2: 1-8.

Reddy M N, Rao Kanna K V, Rao S S, Rao M E. Spectrophotometric methods For the determination of salmeterol xinafoate. Indian Journal of Pharmaceutical Sciences, 2000; 62: 193-195.

Samir A, Salem H, Abdelkawy M. Simultaneous determination of salmeterol xinafoate and fluticasone propionate in bulk powder and seritide ${ }^{\circledR}$ diskus using high performance liquid chromatographic and spectrophotometric method. Pharmaceutica Analytica Acta, 2012; 3: 1-7. 
Siluk D, Kim H, Cole T, Wainer I. HPLC-electrospray mass spectrometric assay for the determination of $(\mathrm{R}, \mathrm{R})$-fenoterol in rat plasma J Pharm Biomed Anal, 2008; 48: 960-964.

Soliman M H, Abdel Moety E. Determination of some antiblockers through spectrophotometric, HPLC and TLC-densitometric methods. International Journal of pharmaceutical, chemical and biological sciences, 2014; 4: 794-801.

Thea Sufernent S. New Spectrophotometric methods for the determination of salmeterol xinafoate. Indian Journal of Pharmaceutical Sciences, 1998; 60: 294-296.

Wang Z, Deng Y, Zhang X. Simultaneous HPLC determination of salmeterol and budesonide in liposome preparation. Chinese Journal of Pharmaceutical Analysis, 2007; 27: 231-233.

Zamuner M L M, Carrion $\mathrm{R} \quad \mathrm{C}$ E, Magalhães $\mathrm{J}$ F. Spectrophotometric determination of fenoterol hydrobromide in pharmaceutical preparations. Revista Brasileira de Ciências Farmacêuticas, 2008; 44: 645-653.

\section{How to cite this article:}

Hammad MA, Omar MA, Awad M. Validation of sensitive spectrophotometric method for determination of Salmeterol xinafoate and Fenoterol hydrobromide via o-Phenanthroline and iron complexation. J App Pharm Sci, 2017; 7 (06): 049-054. 